Cita: Modolo, F.; Menezes, R. P. (2019). Características técnico-táticas dos goleiros de handebol da categoria sub-16: opinião de treinadores brasileiros. Cuadernos de Psicología del Deporte, 19(1), 206221

\title{
Características técnico-táticas dos goleiros de handebol da categoria sub- 16: opinião de treinadores brasileiros
}

\section{U-16 Handball goalkeepers' technical and tactical characteristics: Brazilian coaches' opinions}

\section{Características técnico-tácticas de los porteros de balonmano de la categoría sub-16: opiniones de los entrenadores brasileños}

\author{
Modolo, F. \& Menezes, R. P. \\ ${ }^{1}$ Universidade de São Paulo (USP) - Escola de Educação Física e Esporte de Ribeirão Preto (EEFERP)
}

Financiamento: O presente trabalho foi realizado com apoio da Coordenação de Aperfeiçoamento de Pessoal de Nível Superior - Brasil (CAPES) - Código de Financiamento 001.

\section{RESUMO}

O objetivo deste estudo é identificar e discutir as características técnico-táticas mais relevantes a serem abordadas no processo de dos guarda-redes da categoria sub-16 no andebol, a partir da opinião de um grupo de treinadores brasileiros. Optou-se por uma abordagem qualitativa, a partir de entrevistas semiestruturadas com 19 treinadores de equipas masculinas e/ou femininas da categoria sub-16. Estas equipas participaram em competições organizadas pelas duas maiores ligas de andebol do Estado de São Paulo no ano de 2016. Os testemunhos foram organizados e analisados com base no método do Discurso do Sujeito Coletivo (DSC). Foi possível identificar duas linhas de discursos: o DSC1 referiu-se à importância da posição de base e dos gestos técnicos específicos, com foco principal na execução do movimento; o DSC2 destacou a importância dos processos inerentes à tomada de decisão dos guarda-redes, como percepção de sinais relevantes que podem fornecer subsídios para que o guarda-redes selecione a técnica mais adequada para defender. Embora tenha sido mencionada a importância de diferentes técnicas, os movimentos não devem necessariamente ser treinados de maneira estereotipada, mas orientados à resolução dos problemas apresentados nas situações de jogo, principalmente por ser uma etapa em que a especialização por postos específicos é intensificada. Nesse sentido, os resultados podem ser utilizados para compreender os requisitos dessa etapa de formação, subsidiar a elaboração das sessões de treino para o desenvolvimento técnico e tático do guarda-redes. Os resultados também podem ser generalizados a equipas de outras modalidades, considerando as experiências prévias e as características individuais dos guarda-redes.

Palavras chave: Pedagogia do desporto; Treinador desportivo; Andebol;Guarda-redes. 


\title{
Características técnico-táticas: goleiros cadetes de handebol
}

\begin{abstract}
The aim of this study was to identify and to discuss the main technical tactical aspects to be emphasized in the training of goalkeepers of the under-16 (U-16) handball teams, based on the opinions of a group of Brazilian coaches. We opted for a qualitative approach, based on semi-structured interviews with 19 U-16 teams (male and/or female) coaches who participated in competitions organized by the two main handball leagues of the State of São Paulo in 2016. The speeches were tabulated and analyzed based on the Collective Subject Discourse (CSD) method. Two main discourses were identified: DSC1, which referred to the importance of the basic position and the specific technical gestures, with a main focus on the movement efficiency; and DSC2, which emphasized the importance of goalkeeping decision making, as perceived relevant signals that can provide subsidies for the goalkeeper to select the most appropriate technique to defend. Although the importance of different techniques has been mentioned, they should not be trained in a stereotyped way, but oriented to solve problems presented in the different situations of game, mainly because it is a stage that the specialization by specific positions is intensified. In this sense, the results can be used to understand the requirements of this training stage and to subsidize the organization of the training sessions for the technical and tactical development of the goalkeeper. The results are also generalizable to teams from any context, considering previous experiences and individual characteristics of goalkeepers.
\end{abstract} Keywords: Sport pedagogy; Coaching; Handball; Goalkeper.

\section{RESUMEN}

El objetivo de este estudio fue identificar y discutir las características técnico-tácticas más relevantes a ser abordadas en los entrenamientos de los porteros de la categoría sub-16 en el balonmano, a partir de la opinión de un grupo de entrenadores brasileños. Se optó por un enfoque cualitativo, a partir de entrevistas semiestructuradas con 19 entrenadores de equipos masculinos y/o femeninos de la categoría sub-16. Estos equipos participaron de competiciones organizadas por las dos mayores ligas de balonmano del Estado de São Paulo en el año 2016. Los testimonios fueron tabulados y analizados con base en el método del Discurso del Sujeto Colectivo (DSC). Fue posible identificar dos líneas de discursos principales: el DSC1 se refirió a la importancia de la posición de base y de los gestos técnicos específicos, con enfoque en la ejecución del movimiento; el DSC2 destacó la importancia de los procesos para la toma de decisión de los porteros, como percepción de señales relevantes que pueden proporcionar subsidios para seleccionar la técnica más adecuada para defender. Aunque se ha mencionado la importancia de diferentes técnicas, no necesariamente los movimientos deben ser entrenados de manera estereotipada, pero orientados a la resolución de los problemas presentados en el juego, principalmente por ser una etapa en que la especialización por puestos específicos es intensificada. Los resultados pueden ser utilizados para comprender los requisitos de esa etapa de formación, subsidiar la elaboración de las sesiones de entrenamiento para el desarrollo técnico y táctico del portero. Los resultados también son generalizables a equipos de cualquier contexto, considerando las experiencias previas y las características individuales de los porteros.

Palabras clave: Pedagogía del deporte; Entrenador deportivo; Balonmano; Portero.

Cuadernos de Psicología del Deporte, 19, 1 (enero) 


\section{Modolo, F.; Menezes, R. P.}

\section{INTRODUÇÃO}

O handebol é classificado como um jogo esportivo coletivo (JEC) de cooperação-oposição (Sousa, Sequeira \& Hernandez-Mendo, 2014) e de invasão do espaço de jogo de forma simultânea (Menezes, Marques \& Morato, 2016), no qual duas equipes são organizadas em sistemas ofensivos e defensivos, em que os jogadores ocupam postos específicos com o intuito de cumprir os princípios operacionais inerentes às fases do jogo (Bayer, 1994). Mesmo considerando as especificidades dos postos, é importante que ao longo do processo de ensinoaprendizagem sejam desenvolvidas as competências inerentes a cada um desses (Ehret, Späte, Schubert \& Roth, 2002). Na medida em que os jogadores aproximam-se da fase de especialização no handebol, aumenta-se paulatinamente o treinamento específico (Ehret et al., 2002; Menezes, Reis \& Tourinho Filho, 2015).

De todos os postos específicos defensivos destaca-se, neste estudo, o de goleiro. Embora auxilie no cumprimento dos princípios operacionais dessa fase, o goleiro também participa da fase ofensiva e possui características específicas em ambas as fases quando comparadas aos demais jogadores. Seu principal objetivo defensivo é evitar que a equipe adversária anote o gol, procurando manter um posicionamento que facilite a defesa da bola (Arias Estero, 2009) por meio das técnicas específicas de defesa (Antúnez Medina, 2003). Já a sua participação na fase ofensiva do jogo iniciase com a recuperação da posse da bola, quando esse preconiza o rápido reinício do jogo para a construção da transição ofensiva da sua equipe. Essa transição pode ser realizada a partir de um passe longo, para iniciar um contra-ataque simples ou de um passe curto ao jogador mais próximo para que este inicie um contra-ataque

\footnotetext{
${ }^{1}$ Jogo deliberado: faz referência à prática esportiva com o objetivo de diversão, intrinsecamente motivantes e com gratificação imediata; já a prática deliberada apresenta-se como atividades mais estruturadas, com maior
}

apoiado/sustentado (Arias Estero, 2009; Greco, Ferreira Filho \& Oliveira Junior, 2002).

Assim como recomenda-se para os demais postos específicos, as competências inerentes ao goleiro devem ser desenvolvidas paulatinamente em um processo de ensino-aprendizagem em longo prazo. Esse contexto possibilita apresentar aos goleiros problemáticas cada vez mais complexas e que atendam de fato às situações do jogo formal que vão sendo requeridas ao longo do seu desenvolvimento, concomitantemente ao dos demais jogadores da equipe.

Para que isso seja possível, é necessário conhecer as caraterísticas inerentes à etapa do desenvolvimento na qual se encontram, que fornecem indicativos/subsídios para a seleção de possíveis conteúdos a serem ensinados e das competências a serem construídas. Côtè, Baker e Abernethy (2007) apresentam três estágios de desenvolvimento esportivo, considerando uma possível carreira esportiva a partir de práticas diversificadas em detrimento da especialização precoce: a etapa de amostragem (de 6 a 12 anos de idade), a etapa de especialização (de aproximadamente 13 a 15 anos de idade) e a etapa de investimento (aproximadamente a partir dos 16 anos de idade).

Ao longo do processo de formação esportiva espera-se que o aumento da especificidade em uma modalidade ocorra paulatinamente, cuja premissa também pode ser aplicada ao treinamento especializado dentro dessa, atendendo aos requisitos de cada posto específico (como o goleiro). Cada estágio é pautado pela relação entre os conceitos de jogo deliberado e o de prática deliberada ${ }^{1}$ (Côtè et al., 2007).

Dessa forma, a categoria sub-16, pautando-se no contexto abordado por Côtè et al. (2007), é marcada pela transição entre a etapa de especialização e a de investimento, na qual haverá início do processo de investimento específico em

sistematização, com regras explícitas, sem recompensas imediatas e que objetiva a melhoria do desempenho (Côtè et al., 2007; Fraser-Thomas, Côté \& Deakin, 2005). 


\section{Características técnico-táticas: goleiros cadetes de handebol}

dada modalidade visando à busca por maior rendimento competitivo. Justifica-se a escolha da categoria sub-16 neste estudo pelo fato de ser a categoria sugerida para a especialização do goleiro de handebol (Greco \& Benda, 2002; Santos \& Menezes, 2015). Considerando o contexto brasileiro esta é uma categoria na qual há jogadores iniciando na prática do handebol (Menezes, 2010), quando a recomendação seria a de preconizar o domínio das habilidades específicas que permitam a melhoria de rendimento específico na modalidade, características da etapa de especialização (Greco \& Benda, 2002; Santos \& Menezes, 2015).

Diante desse contexto, o objetivo deste estudo é identificar e discutir as principais características técnico-táticas, na opinião dos treinadores brasileiros, a serem abordadas nos treinamentos dos goleiros da categoria sub-16 no handebol.

\section{MÉTODOS}

\section{Desenho}

O desenho observacional deste estudo é nomotético - entrevista e análise dos discursos de treinadores de handebol; pontual - por ser um corte transversal, sem continuidade; e multidimensional - admite diversas dimensões para $o$ estudo das capacidades a serem desenvolvidas nos goleiros da categoria sub-16 no handebol (Anguera, Blanco-Villaseñor, Hernández-Mendo \& Losada, 2011).

A opção pela abordagem qualitativa pautou-se não apenas na representatividade numérica de dados, mas na busca pela compreensão e atribuição de significados de um determinado grupo, organização ou fenômeno social sobre dado assunto (Triviños, 1987; Silveira \& Córdova, 2009), sem necessariamente comparar grupos, prever comportamentos ou provar um dado modelo (Ato, López \& Benavente, 2013). Flick (2009) considera como aspectos fundamentais da pesquisa qualitativa a perspectiva dos participantes e a reflexividade do pesquisador para com essas perspectivas, neste caso as características técnico-táticas a serem desenvolvidas nos goleiros da categoria sub-16 do handebol na opinião de treinadores.

\section{Participantes}

Participaram deste estudo 19 treinadores da categoria sub-16, de equipes do sexo masculino e/ou feminino e que participaram de competições organizadas pelas duas maiores ligas de handebol do Estado de São Paulo no ano de 2016. A escolha por essas competições justificouse pela grande abrangência territorial de ambas e pela proximidade entre os pesquisadores e os treinadores.

Por se tratar de um estudo envolvendo seres humanos, o mesmo foi submetido e aprovado por um Comitê de Ética em Pesquisa institucional. No momento da entrevista os treinadores assinaram um Termo de Consentimento Livre e Esclarecido descrevendo os objetivos e os procedimentos do estudo, garantindo a utilização dos seus depoimentos estritamente para fins acadêmicos e o sigilo das informações pessoais. As características dos treinadores entrevistados estão apresentadas no Quadro 1.

Quadro 1 - Características dos treinadores entrevistados

\begin{tabular}{cccccc}
\hline Treinador & Idade & $\begin{array}{c}\text { Tempo como treinador } \\
\text { de Handebol (anos) }\end{array}$ & $\begin{array}{c}\text { Atuação no Handebol } \\
\text { Escolar }\end{array}$ & $\begin{array}{c}\text { Outra Função } \\
\text { Profissional }\end{array}$ & Pós-Graduação \\
\hline S1 & 54 & 30 & Não & Sim & Não \\
S2 & 43 & 21 & Sim & Sim & Sim $^{1}$ \\
S3 & 32 & 4 & Sim & Não & Não \\
S4 & 35 & 13 & Sim & Sim & Não \\
\hline
\end{tabular}


Modolo, F.; Menezes, R. P.

\begin{tabular}{|c|c|c|c|c|c|}
\hline S5 & 45 & 21 & Sim & Não & $\operatorname{Sim}^{1}$ \\
\hline S6 & 48 & 17 & Sim & Não & $\operatorname{Sim}^{1}$ \\
\hline S7 & 31 & 12 & Não & Sim & $\operatorname{Sim}^{1,2}$ \\
\hline S8 & 43 & 21 & Sim & $\mathrm{Sim}$ & Não \\
\hline S9 & 55 & 24 & Não & Não & $\operatorname{Sim}^{1}$ \\
\hline $\mathrm{S} 10$ & 34 & 14 & Sim & $\mathrm{Sim}$ & $\mathrm{Sim}^{3}$ \\
\hline $\mathrm{S} 11$ & 34 & 14 & $\mathrm{Sim}$ & $\mathrm{Sim}$ & Não \\
\hline $\mathrm{S} 12$ & 37 & 7 & Sim & Não & $\mathrm{Sim}^{3}$ \\
\hline $\mathrm{S} 13$ & 44 & 19 & Não & Não & $\operatorname{Sim}^{1}$ \\
\hline $\mathrm{S} 14$ & 44 & 16 & Não & $\mathrm{Sim}$ & Não \\
\hline $\mathrm{S} 15$ & 48 & 26 & Sim & Sim & Não \\
\hline $\mathrm{S} 16$ & 53 & 22 & $\mathrm{Sim}$ & Não & $\operatorname{Sim}^{1}$ \\
\hline $\mathrm{S} 17$ & 36 & 15 & Sim & Sim & Não \\
\hline $\mathrm{S} 18$ & 30 & 1,5 & Não & $\mathrm{Sim}$ & Não \\
\hline $\mathrm{S} 19$ & 30 & 4 & $\mathrm{Sim}$ & $\mathrm{Sim}$ & $\operatorname{Sim}^{1,3}$ \\
\hline
\end{tabular}

Todos os entrevistados são graduados em Educação Física (Licenciatura Plena, Bacharelado e/ou Licenciatura) e um deles é Mestre em Educação Física. Em relação aos cursos de pós-graduação lato sensu, oito treinadores concluíram um curso relacionado especificamente ao handebol e três concluíram cursos em áreas correlatas. A média de idade dos entrevistados foi de 40,8 anos ( \pm 8,3; mín:30; máx:55). Os participantes possuíam tempo médio de atuação profissional com o handebol de 15,9 anos ( $\pm 7,8$; mín:1,5; máx:30), em diferentes categorias e contextos (escolar, clubes e equipes competitivas).

Dos treinadores entrevistados, 13 dirigiram/dirigem equipes de handebol no contexto escolar, âmbito no qual alguns desses iniciaram sua carreira, seja nas aulas de Educação Física ou por meio de projetos de iniciação esportiva. Além disso, 12 treinadores disseram que exerciam outra função profissional para além da função de treinador de handebol da categoria sub-16 na época das entrevistas.

\section{Instrumento de entrevista}

Neste estudo foi utilizada a entrevista semiestruturada como instrumento da pesquisa qualitativa, por permitir a expressão do pensamento dos participantes sobre a temática em voga de forma mais aprofundada (Marconi \& Lakatos, 2011). Esse tipo de entrevista se caracteriza pela utilização de perguntas abertas, na qual as questões pré-definidas servem como uma diretriz ao objetivo da pesquisa (Flick, 2009; Marconi \& Lakatos, 2011; Thomas, Nelson \& Silverman, 2012).

O participante é livre para responder às perguntas de acordo com o seu entendimento, enquanto o entrevistador pode realizar perguntas complementares para aprofundar na temática específica (Flick, 2009; Marconi \& Lakatos, 2011; Thomas et al., 2012). A entrevista semiestruturada pode ser considerada como um instrumento crucial para o processo de desvendar as especificidades inerentes ao contexto de cada esporte (Gómez-Millan \& Esquiva, 2017).

Como a intenção deste estudo foi de identificar as características técnico-táticas a serem desenvolvidas nos goleiros da categoria sub-16 do handebol na opinião de treinadores, o instrumento de entrevista utilizado neste estudo 


\section{Características técnico-táticas: goleiros cadetes de handebol}

foi adaptado a partir da proposta apresentada por Menezes (2011) e foi dividido em dois blocos, assim constituídos: 1) dados pessoais, formação acadêmica e atuação profissional - para aquecimento do entrevistado e para diminuir uma possível inibição causada pelo gravador (Triviños, 1987); 2) características dos goleiros na categoria sub-16.

Inicialmente, partiu-se da seguinte pergunta norteadora: "Na sua opinião, quais são as principais características técnico-táticas a serem desenvolvidas pelo goleiro de handebol nesta categoria?". Por se tratar de um estudo que partiu de entrevistas semiestruturadas, novas questões surgiram ao longo das entrevistas, que possibilitaram aprofundar na temática em questão.

\section{Procedimentos para as entrevistas}

Os procedimentos para a realização das entrevistas foram pautados na proposta de Triviños (1987), sendo apresentados em ordem cronológica: 1) definição dos critérios para inclusão dos participantes; 2) contato inicial via email, telefone ou redes sociais para apresentação do estudo; 3) agendamento da entrevista em momento que não concorresse com a atividade profissional do treinador, garantindo a atenção exclusiva para a entrevista; 4) entrevista gravada na íntegra e anotações de pontos relevantes; 5) transcrição da entrevista.

Pautando-se nas necessidades e disponibilidades dos treinadores, bem como nas limitações financeiras para a realização das entrevistas (altos custos de deslocamentos, estadia e alimentação, pelo fato de os treinadores residirem em regiões distantes do Estado de São Paulo), essas foram realizadas em três condições distintas: pessoalmente (in loco - modo preferencial para produção dos dados), via Skype (caso não fosse possível o contato pessoal) e, em último caso, via aplicativo WhatsApp (quando ambas as alternativas anteriores não foram possíveis). Os procedimentos específicos para cada caso estão apresentados abaixo:
- Entrevistas in loco $(\mathrm{n}=5)$ : foram realizadas em locais sem ruídos externos que comprometessem a resposta do participante, seja em relação à gravação ou à sua atenção. A entrevista foi gravada na íntegra por meio de um gravador de voz no celular do pesquisador;

- Entrevistas via Skype $(n=3):$ a entrevista foi realizada por meio de uma chamada de vídeo ao vivo, sendo arquivada por meio de um plug-in de gravação da chamada online

- Entrevistas via WhatsApp ( $\mathrm{n}=11)$ : caso o treinador não possuísse ou não tivesse afinidade com o Skype, foi sugerida a realização da entrevista pelo aplicativo WhatsApp, por meio da função de gravação de áudios. Nesta condição, foi gravado o áudio com a pergunta e o treinador pode responder em momento oportuno a partir de mensagem de áudio.

Os arquivos de áudio contendo gravação das entrevistas, independentemente da sua forma (in loco, via Skype ou WhatsApp), foram armazenados em nuvem por proporcionar $\mathrm{o}$ acesso pelos pesquisadores a partir de qualquer dispositivo. Durante a entrevista o pesquisador também realizou anotações de aspectos provenientes das experiências dos treinadores, que serviu para solucionar eventuais dúvidas do entrevistado em relação a qualquer uma das questões do instrumento de entrevista.

Após a finalização da entrevista, o pesquisador procedeu à sua transcrição, geralmente iniciando-a no mesmo dia pelo fato de o discurso ainda estar latente (Oliver, Serovich \& Mason, 2005), juntamente com as anotações realizadas. Ao serem completadas, as transcrições foram enviadas aos treinadores como forma de validar seu conteúdo e garantir a sua confiabilidade.

Análise das entrevistas 


\section{Modolo, F.; Menezes, R. P.}

Para a análise das entrevistas optou-se pelo método do Discurso do Sujeito Coletivo (DSC), que consiste em tabular, analisar e interpretar os discursos provenientes das entrevistas de forma qualitativa (Lefèvre \& Lefèvre, 2012). O DSC é fundamentado na Teoria das Representações Sociais apresentada por Serge Moscovici, que visa identificar as ideias socialmente compartilhadas em um determinado grupo, bem como as relações entre sujeito e objeto para a construção do conhecimento (Crusoé, 2004). Todavia, este método propõe a identificação de todas as ideias existentes dentro de um determinado grupo social e não somente aquelas que são mais compartilhadas (Lefèvre \& Lefèvre, 2012).

O DSC baseia-se na ideia de considerar a discursividade, que é característica do pensamento coletivo, em todos os momentos da pesquisa, desde a elaboração do instrumento de entrevista até o momento de apresentação dos resultados (Lefèvre \& Lefèvre, 2012). Para isso, esse método baseia-se principalmente em três figuras metodológicas: a) expressões-chave $\mathrm{ECH}$ : trechos literais do discurso que revelam a sua essência; b) ideias centrais - IC: expressões que descrevem sucinta, precisa e fidedignamente o significado dos discursos analisados e de cada grupo de $\mathrm{ECH}$; e c) o próprio DSC - "discursosíntese" na primeira pessoa do singular que representa o pensamento de uma determinada comunidade sobre um determinado tema, a partir do agrupamento das diferentes ECH com a mesma IC (Lefèvre \& Lefèvre, 2012).

As IC identificadas nos discursos dos treinadores são mutuamente excludentes e apresentam o caráter de exaustividade (Anguera \& Hernández-Mendo, 2013), porque respectivamente cada $\mathrm{ECH}$ selecionada dos discursos é inerente a apenas uma IC e cada ECH que se referiu a alguma IC ainda não identificada permitiu a criação de outra categoria. De modo a garantir um adequado controle da qualidade dos dados, foi adotada como confiabilidade dos dados a concordância consensual (qualitativa) por dois pesquisadores dos DSC elaborados (Anguera \& Hernández-Mendo, 2013; Wright, Carling, Lawlor \& Collins, 2016).

Entendendo que cada IC corresponde a uma categoria de observação elaborada a partir dos discursos dos treinadores, em consonância com os diferentes autores pesquisados, foi possível identificar duas categorias principais. A primeira refere-se aos aspectos técnicos para o desenvolvimento de goleiros de handebol, como a posição de base e os diferentes gestuais específicos. Já a segunda refere-se a elementos inerentes à capacidade de tomada de decisão dos goleiros.

No Quadro 2 estão apresentados os agrupamentos das temáticas abordadas pelos treinadores, sendo a primeira coluna destinada ao rótulo atribuído ao $\mathrm{DSC}$, a segunda às categorias que sustentam a rotulação do DSC (semelhante à concepção das diversas IC) e a terceira às características técnicas e/ou táticas apontadas nos discursos dos treinadores inerentes a cada categoria. Destaca-se que esse foi desenvolvido com base na proposta de Anguera e HernándezMendo (2013) e Anguera, Portell, ChacónMoscoso e Sanduvete-Chaves (2018), quando versaram sobre os sistemas de categorias (cumprindo os supramencionados critérios de exaustividade e mútua exclusividade).

\begin{tabular}{|c|c|c|}
\hline DSC & Categoria & Características \\
\hline \multirow{2}{*}{$\begin{array}{c}\text { Aspectos técnicos } \\
\text { (DSC1) }\end{array}$} & Posição-base & Postura, braços altos e corpo estendido \\
\hline & Técnica para defesa alta & $\begin{array}{l}\text { Defesas com os braços estendidos, defesas } \\
\text { com saltos, saída em "X" }\end{array}$ \\
\hline
\end{tabular}




\section{Características técnico-táticas: goleiros cadetes de handebol}

\begin{tabular}{|c|c|c|}
\hline & $\begin{array}{l}\text { Técnica para defesa em meia } \\
\text { altura }\end{array}$ & $\begin{array}{l}\text { Defesas com os braços abertos e utilização das } \\
\text { pernas de forma simultânea e coordenada }\end{array}$ \\
\hline & Técnica para defesa baixa & $\begin{array}{l}\text { Defesas com queda, deslocamentos baixos, } \\
\text { "espacatos" }\end{array}$ \\
\hline & Passe para contra-ataque & $\begin{array}{l}\text { Passe para contra-ataque direto ou } \\
\text { sustentado; reposição rápida da bola em jogo }\end{array}$ \\
\hline \multirow{4}{*}{$\begin{array}{c}\text { Elementos } \\
\text { inerentes à } \\
\text { tomada de decisão } \\
\text { (DSC2) }\end{array}$} & $\begin{array}{l}\text { Identificação das características } \\
\text { do atacante }\end{array}$ & $\begin{array}{l}\text { Trajetórias, braço de arremesso, locais de } \\
\text { finalização }\end{array}$ \\
\hline & Colaboração com a defesa & $\begin{array}{l}\text { A defesa fica responsável por defender um } \\
\text { lado e o goleiro outro }\end{array}$ \\
\hline & Fintas do goleiro & $\begin{array}{l}\text { Avançar até os } 4 \mathrm{~m} \text { e voltar para induzir o } \\
\text { arremesso do atacante e facilitar a ação do } \\
\text { goleiro }\end{array}$ \\
\hline & Antecipar a ação do atacante & $\begin{array}{l}\text { Perceber o que o atacante vai fazer e antecipar } \\
\text { a sua reação momentos antes do arremesso }\end{array}$ \\
\hline
\end{tabular}

Dado o registro em arquivo separado dos áudios e das transcrições das entrevistas na íntegra, foi possível recorrer aos discursos originais como forma de verificação de dúvidas. Aponta-se, ainda, que cada IC sintetiza a temática central abordada por cada DSC, assim como proposto em outros estudos com treinadores de handebol (Menezes, Marques \& Morato, 2016; Menezes, Marques \& Nunomura, 2015, 2017).

$\mathrm{Na}$ seção "Resultados" os DSC serão apresentados na íntegra, com a procedência das falas apontada de maneira sobrescrita. Destaca-se que o objetivo não foi a busca por variáveis quantificáveis, mas revelar os pensamentos dos treinadores sobre as principais características técnico-táticas a serem desenvolvidas nos goleiros da categoria sub-16.

\section{RESULTADOS}

No Quadro 3 estão apresentados dois DSC: o DSC1, proveniente da IC-1: "Posição base e técnica específica", que reuniu as opiniões compartilhadas por 17 treinadores; e o DSC2, proveniente da IC-2: "Capacidade de tomada de decisão", a partir das opiniões compartilhadas por 13 treinadores.

\section{Quadro 3: IC e DSC referentes às principais características técnico-táticas a serem desenvolvidas pelo goleiro de handebol na categoria sub-16}

IC-1: Posição base e técnica específica $(\mathrm{S} 1 ; \mathrm{S} 3 ; \mathrm{S} 4 ; \mathrm{S} 5 ; \mathrm{S} 6 ; \mathrm{S} 7 ; \mathrm{S} 8 ; \mathrm{S} 9 ; \mathrm{S} 10 ; \mathrm{S} 11 ; \mathrm{S} 12 ; \mathrm{S} 13 ; \mathrm{S} 14 ; \mathrm{S} 16 ; \mathrm{S} 17 ; \mathrm{S} 18 ; \mathrm{S} 19)$ DSC1: Na categoria sub-16, quando se fala em capacidade técnica de um goleiro, ele tem que saber perfeitamente a execução de um deslocamento para uma defesa baixa, para uma defesa meia-altura e para uma defesa alta ${ }^{\mathrm{S} 1, \mathrm{~S} 4, \mathrm{~S} 11, \mathrm{~S} 12, \mathrm{~S} 13, \mathrm{~S} 14, \mathrm{~S} 19}$. Além disso, o trabalho postural, a posição base do goleiro com o braço alto e o corpo sempre estendido são muito importantes para que ele tenha um bom posicionamento em relação a bola $\mathrm{S}^{\mathrm{S} 1, \mathrm{~S} 3, \mathrm{~S} 4, \mathrm{~S} 5, \mathrm{~S} 6, \mathrm{~S} 10, \mathrm{~S} 11, \mathrm{~S} 18, \mathrm{~S} 19}$, em relação a trave com os ângulos longo e curto $\mathrm{S} 6, \mathrm{~S} 7, \mathrm{~S} 8, \mathrm{~S} 12, \mathrm{~S} 13, \mathrm{~S} 16$, procurando manter o seu corpo sempre de frente ao arremesso adversário ${ }^{\mathrm{S} 6, \mathrm{~S} 8, \mathrm{~S} 12, \mathrm{~S} 13, \mathrm{~S} 16, \mathrm{~S} 17, \mathrm{~S} 18}$. O goleiro ele já tem que saber fazer algumas coisas, como uma queda, um espacato, um " $\mathrm{X}$ " bem feito, atacar a bola, ter essa noção de saídas para defender a bola ${ }^{\mathrm{S} 1, \mathrm{~S} 3, \mathrm{~S} 5, \mathrm{~S} 7, \mathrm{~S} 11, \mathrm{~S} 13}$, isso somado a um bom trabalho coordenativo para economizar energia ${ }^{\mathrm{S} 10}$. Na parte ofensiva, ele tem que ter um bom passe para executar bem o lançamento direto de contra-ataque ou mesmo para conseguir repor rapidamente a bola ${ }^{\mathrm{S} 2, \mathrm{~S} 6, \mathrm{~S} 9, \mathrm{~S} 10, \mathrm{~S} 11, \mathrm{~S} 12}$. Ao final dessa categoria, eu espero que pelo menos a questão técnica já esteja melhor, o gesto técnico já tem que estar pronto para o juvenil ${ }^{\mathrm{S} 4, \mathrm{~S} 11}$. 


\section{Modolo, F.; Menezes, R. P.}

IC-2: Capacidade de tomada de decisão (S1; S2; S3; S4; S5; S6; S7; S9; S10; S13; S14; S16; S17)

DSC2: O grande problema dos goleiros, independente da escola, é que eles mecanizam algumas figuras e realizam elas em qualquer situação, desconsiderando a variação da finalização do adversário ${ }^{55}$. $\mathrm{O}$ goleiro tem que ser capaz de fazer uma movimentação diferente para diversos tipos de arremesso, decidindo o seu movimento técnico em função do que o atacante demonstrar ${ }^{\mathrm{S} 1, \mathrm{~S} 5, \mathrm{~S} 10, \mathrm{~S} 13, \mathrm{~S} 16}$, como as características dos atacantes que mais finalizam ${ }^{\mathrm{S} 1, \mathrm{~S} 2, \mathrm{~S} 4, \mathrm{~S} 9}$, suas trajetórias pré-arremesso ${ }^{\mathrm{S} 4, \mathrm{~S} 6, \mathrm{~S} 14}$ e do trabalho colaborativo com a defesa, no qual a defesa fecha um lado do gol e o atacante outro ${ }^{\mathrm{S} 2 \mathrm{~S} 17}$. A ideia é tentar visualizar a bola antes de fazer a movimentação ${ }^{\mathrm{S} 14}$ e dificultar a leitura do atacante ao realizar algumas fintas, como avançar até a linha dos $4 \mathrm{~m}$ e retornar à posição inicial para induzir um arremesso de vaselina ${ }^{\mathrm{S} 4, \mathrm{~S} 6, \mathrm{~S} 7, \mathrm{~S} 10, \mathrm{~S} 17}$. Ele tem que ser capaz de decidir o momento de explodir em " $X$ " e ainda procurar antecipar a ação dos atacantes para chegar inteiro na bola e conseguindo se destacar dessa forma ${ }^{\mathrm{S} 1, \mathrm{~S} 3, \mathrm{~S} 6, \mathrm{~S} 17}$. Mas o mais importante é ele entender o porquê ele está tomando determinadas decisões e executando certas ações. Por isso eu acabo dando mais ênfase nesse aspecto de entender o jogo e tomar a decisão em cima disso ${ }^{\mathrm{S}}$, porque o mais importante é ele tentar defender a bola e estando bem posicionado, ele tem mais chance de defender, independente se o gesto está correto ou não ${ }^{\mathrm{S} 4 \mathrm{~S} 16}$.

\section{DISCUSSÃO}

Embora haja indissociabilidade entre as características técnicas e táticas apresentadas no DSC1 e no DSC2, ambas serão discutidas sequencialmente, com relações estabelecidas ao longo da seção. Os treinadores apontaram no DSC1 a necessidade do desenvolvimento de características técnicas específicas dos goleiros, como a sua posição-base, as técnicas de defesa (alta, baixa e meia altura), a saída em "X", o "espacato" e o passe para repor a bola em jogo ou para fazer o lançamento direto para o contraataque. Fica evidente que para o desenvolvimento das técnicas específicas é importante o desenvolvimento de um bom repertório motor que subsidie as decisões tomadas pelos goleiros ao longo do jogo, reforçando que as questões técnicas estão intimamente relacionadas com às questões táticas apresentadas pelo jogo (Alsharji \& Wade, 2016; Loffing \& Hagemann, 2014)

O goleiro possui suas especificidades técnicas que consistem no domínio dos deslocamentos para se posicionar no gol e nas diferentes técnicas para a defesa (Antúnez Medina \& García Parra, 2008), as quais possibilitam reduzir os ângulos de arremesso dos atacantes e defender arremessos em diferentes alturas no gol. Para isso também é importante considerar as características individuais do goleiro, possibilitando adaptações na execução dos movimentos - de construção individual - de acordo com a situação com a qual se depara, e não necessariamente seguindo apenas padrões de movimentos pré-estabelecidos e/ou estereotipados (Arias Estero, 2009; Loffredo \& Greco, 2002; Thiengo, Vitório \& Ferreira, 2006).

Para atingir o domínio técnico desejado destaca-se a relevância de exercícios/atividades que enfatizem o controle postural e a posição base do goleiro de handebol. A posição base caracteriza-se como a forma pela qual o goleiro se mantém posicionado para conseguir reagir em detrimento do arremesso (para qualquer lado e altura), dependendo dos sinais do atacante (Loffredo \& Greco, 2002) que deve permitir, ainda, movimentos com rapidez, com saídas e saltos em equilíbrio a partir de um posicionamento perpendicular à trajetória da bola (Zeir, 1981). Tal posição consiste em manter braços e pernas em semi-flexão, preparando-os para a extensão no momento da ação defensiva, com o tronco ligeiramente inclinado à frente, dividindo o peso corporal de maneira uniforme e estável em ambas as pernas e voltando as mãos para a bola (Arias Estero, 2009; Loffredo \& Greco, 2002; Thiengo et al., 2006).

Quando comparamos o DSC1 com a descrição da posição-base do goleiro de handebol apresentada pelos autores supracitados, são identificadas semelhanças em relação aos objetivos, porém diferindo em aspectos como o 


\section{Características técnico-táticas: goleiros cadetes de handebol}

posicionamento dos braços (sempre no alto, segundo o DSC1) e o corpo estendido. A concepção generalista sobre a posição-base do goleiro apresentada pelos treinadores desconsidera as aptidões individuais desse, como os fatores antropométricos e a própria especificidade da execução das técnicas. Caso tal generalização seja levada à prática, há o risco de formar goleiros pouco eficazes do ponto de vista técnico-tático para responder às demandas impostas pelas situações do jogo, uma vez que não há necessidade, por exemplo, de manter os braços sempre altos quando há elementos que permitam identificar arremessos nas zonas mais baixas do gol. O posicionamento inadequado dos braços combinado com o desequilíbrio no momento de um salto para tentar defender a bola são os erros mais recorrentes na execução da posição-base do goleiro de handebol (Zeir, 1992). Sugere-se enfatizar durante o processo de ensinoaprendizagem que a posição de base não é fixa e deve considerar também os indicativos provenientes da situação de jogo, que podem alterar a forma como o goleiro se prepara para tentar defender um arremesso.

Além da posição-base, o DSC1 aponta que o goleiro deve ser capaz de executar outras ações técnicas para defender, como o espacato, a defesa em "X", ter noções de avanço e retorno de posicionamento e também os deslocamentos para a defesa. Quanto aos deslocamentos, a ideia consiste em estar posicionado e identificar qual será a ação do atacante com bola, para então deslocar-se rapidamente para o local do gol onde será feito o arremesso, tentando manter a posição de base sempre que possível (Loffredo \& Greco, 2002), o que facilitaria a execução das possíveis técnicas de defesa.

Em relação a esses deslocamentos do goleiro de handebol, Arias Estero (2009) descreve quatro tipos: a) aquele que o goleiro se desloca em posição-base de um lado ao outro do gol para acompanhar a movimentação da bola; b) aquele em que o goleiro tem que buscar defender o lado do gol para onde foi feito o arremesso, para impedir que a bola entre no gol; c) aquele que o goleiro executa após o descrito anteriormente, com o intuito de retomar a posse da bola quando ainda está dentro da área; e por último, d) após uma ação de defesa para retomar a posição base no gol e o seu equilíbrio, principalmente caso haja rebote a favor dos atacantes. Considerando os tipos de deslocamentos do goleiro apresentados pelo autor supracitado, percebe-se que o DSC1 destaca a execução dos deslocamentos relacionados com as tentativas de defesa e recuperação da posse de bola.

No entanto, não fica claro no DSC1 a importância atribuída aos deslocamentos anteriores à defesa do goleiro, sem qualquer tipo de indicativos sobre como o goleiro deve movimentar-se antes do arremesso adversário. Este é um aspecto que merece destaque, pois o deslocamento anterior à defesa vai influenciar diretamente na posição-base e na escolha das técnicas específicas para tentar defender a bola. Sugere-se que o goleiro deve se movimentar próximo ao gol e acompanhar a direção da movimentação da bola pelo ataque adversário, procurando manter a sua posição-base de frente com o jogador em posse de bola.

Outro aspecto apontado pelo DSC1 foi o passe longo para um contra-ataque direto e a reposição de bola rápida como elementos de responsabilidade do goleiro de handebol. Essas são duas características apontadas como fundamentais para o bom desempenho individual ofensivo do goleiro (Antúnez Medina, 2003), que deve ser capaz de repor a bola em jogo rapidamente e estar atento para fazer $o$ lançamento de contra-ataque direto ou iniciá-lo de maneira sustentada (Menezes, 2011). Nesse contexto, o domínio da posição-base e das ações de deslocamento para a defesa são técnicas fundamentais para o bom desempenho do goleiro. Nesse aspecto, há a concordância entre o DSC1 e os diferentes autores mencionados.

Espera-se que o goleiro domine as técnicas específicas ao final da categoria sub-16, uma vez que, nas categorias posteriores (sub-18 e sub-21) o objetivo vai ser melhorar o desempenho do goleiro para que jogue em níveis de 


\section{Modolo, F.; Menezes, R. P.}

rendimento cada vez mais elevados (Greco \& Benda, 2002), o que corrobora o trecho final do DSC1.

Considerando o modelo de formação esportiva proposto por Côtè et al. (2007) e o DSC1 percebe-se que a categoria sub-16 marca o início da etapa de investimento, não apenas pela faixa etária, mas pelos objetivos e habilidades técnico-táticas que os treinadores do DSC1 esperam que os seus atletas dominem ao final dessa, o que demonstra uma concordância entre o modelo teórico e o que pensam os treinadores. Salienta-se que as habilidades específicas devem ser desenvolvidas ao longo do tempo, permitindo que os goleiros vivenciem diferentes experiências que possam ajudar a refinar o domínio de determinadas habilidades passando por diferentes etapas de formação esportiva (Torregrosa, Chamorro \& Ramis, 2016).

Nesse contexto, proporcionar experiências em diferentes ambientes e modalidades ao longo das etapas de diversificação e de especialização, anteriores à etapa de investimento, pode favorecer o aprendizado das habilidades específicas até a categoria sub-16, momento no qual o aumento da prática deliberada vai ter como objetivo melhorar o desempenho das habilidades já aprendidas nas fases anteriores. Para isso, o treinador pode utilizar diferentes procedimentos pedagógicos e métodos de ensino com o intuito de desenvolver as diferentes competências para a formação do jogador de handebol (Menezes, 2018).

No entanto, deve-se considerar que muitos jogadores iniciam o treinamento no handebol nessa categoria no contexto brasileiro (Menezes, 2010), com poucas vivências esportivas anteriores, incluindo também vivências em outras modalidades, o que pode subestimar ou superestimar capacidades como a coordenação motora específica e a construção das técnicas de defesa. Tal constatação ainda possibilita, neste caso, adotar possíveis procedimentos pedagógicos para o desenvolvimento de competências que subsidiem as requeridas na categoria sub-16, não enfatizadas nas categorias anteriores justamente pelo início tardio na prática sistematizada do handebol. Isso significa que o goleiro poderá levar um tempo maior para entender o jogo e dominar os conceitos principais do posto específico, como possuir um bom posicionamento e realizar defesas a partir dos gestos técnicos específicos.

No DSC2 os treinadores referiram-se ao fato de que as características técnicas dos goleiros subsidiarão as decisões tomadas em diferentes situações, a partir das suas escolhas na tentativa de realizar a defesa. Essa perspectiva visa dar suporte ao desenvolvimento do jogo tático do goleiro, que o permite escolher dentre as ações técnicas que sabe executar para responder a uma situação de jogo específica, o que é denominado de tomada de decisão.

A tomada de decisão no esporte pressupõe selecionar uma dentre várias respostas possíveis a uma dada situação de jogo. Para que isso ocorra, existem alguns processos subjacentes à tomada de decisão que envolvem a percepção - identificação dos sinais relevantes da situação-problema; a atenção - seleção dos estímulos percebidos e, de acordo com a experiência, focaliza o que se quer perceber; a memória - que verifica se o estímulo já foi vivenciado e as possíveis respostas; e a antecipação - possibilita antever uma resposta frente à situação que está prestes a ocorrer, baseando-se nas informações provenientes da memória (Matias \& Greco, 2010).

Como resultado de um processo de ensino-aprendizagem pautado no desenvolvimento da criticidade do jogador e no entendimento dos "porquês" em executar determinadas ações, espera-se que o goleiro não apresente ações técnicas estereotipadas, mas que compreenda os estímulos da situação de jogo e selecione a ação técnico-tática necessária para responder de forma efetiva à uma situação específica (Pascual Fuertes \& Peña Barceló, 2006). Assim sendo, mais importante do que "como" realizar determinado gesto técnico é entender o "porquê" e "quando" esse deve ser utilizado, respondendo de forma eficaz às 


\section{Características técnico-táticas: goleiros cadetes de handebol}

situações apresentadas, como suscitado por Garganta (1998).

Portando, o DSC2 corrobora a ideia supracitada e aponta como problema a mecanização dos gestos técnicos em qualquer situação, sem considerar as variações das finalizações dos atacantes, ou seja, o contexto de suas decisões. Outro trecho do DSC2 envolve aspectos como a percepção e a atenção aos sinais mais importantes do jogo, que subsidiam a antecipação das respostas para tentar defender os arremessos. Por meio da identificação de aspectos como as trajetórias dos atacantes e os tipos de arremessos, por exemplo, o goleiro pode ajustar seu posicionamento (avançar, retroceder, deslocar-se lateralmente), fintar e pensar em estratégias para induzir o atacante a agir como ele deseja, o que torna imprescindível o treinamento das capacidades de percepção e antecipação para o goleiro de handebol (Alsharji \& Wade, 2016; Loffing \& Hagemann, 2014; Sá, Gomes, Saavedra \& José Fernandez, 2015), em especial, na categoria sub-16 (Greco \& Benda, 2002)

Concebendo o desenvolvimento das competências dos goleiros em uma perspectiva de longo prazo, nas categorias anteriores à proposta deste estudo, como as categorias sub-12 e sub-14, espera-se que as vivências no posto específico suscitem, inicialmente, a busca por defender o arremesso. Ao goleiro deve ser problematizado o fato de defender o arremesso para, então, identificar que pode haver a necessidade de se buscar "como" defender, para então enfatizar o gesto técnico. Tal ideia corrobora os apontamentos de Graça e Mesquita (2015) de que o ensino deva pautar-se inicialmente na necessidade do aprendiz de começar a apreciar a necessidade tática de melhorar a técnica específica que seja necessária para a situação de jogo específica.

Diferentes autores apresentaram propostas de treinamento para o goleiro de handebol a partir do desenvolvimento das capacidades de percepção e antecipação. Pascual Fuertes e Peña Barceló (2006) apresentaram uma proposta de treinamento das capacidades supracitadas diante de arremessos da primeira linha ofensiva (9m). A proposta baseou-se em dividir o arremesso em quatro fases e, em cada uma dessas, o goleiro deveria observar determinados sinais para preparar a sua estratégia de defesa. Em um estudo posterior, Pascual Fuertes (2007) propôs um modelo de treinamento para o goleiro de handebol baseado no tempo total de ação do goleiro, subdividido em três fases: 1) momento prévio a soltura da bola da mão do atacante; 2) tempo de voo da bola até chegar ao goleiro; e 3) tempo de chegada da bola no goleiro. Em cada fase há critérios específicos a serem observados para a definição da decisão a ser tomada pelo goleiro.

Em outros estudos, Antúnez Medina, García Parra, Argudo Iturriaga, Ruiz Lara \& Arias Estero (2009, 2010a, 2010b) desenvolveram uma proposta de treinamento perceptivo-motor para uma goleira de handebol, de acordo com a situação de jogo e o posicionamento do atacante na quadra. Ao final do treinamento verificou-se, por meio de um protocolo específico de observação de jogos ao vivo ou por vídeo, que a goleira submetida ao modelo de treinamento melhorou sua eficácia em competição.

Apesar das diferenças entre cada proposta de treinamento, ambas objetivaram a melhoria das capacidades envolvidas na tomada de decisão do goleiro, panorama esse que corrobora os apontamentos do DSC2, para o qual o goleiro deve ser capaz de visualizar a bola antes de movimentar-se. Entende-se, portanto, que não é somente a bola que deve ser observada de maneira isolada, pois há outras características - como as trajetórias dos atacantes e os tipos de arremessos executados - que influenciam na execução do arremesso. Porém, percebe-se que há uma preocupação por parte dos treinadores em desenvolver as capacidades de percepção, antecipação e tomada de decisão em situação de jogo na categoria sub-16. Contudo, há dúvidas se de fato os treinadores desenvolvem essas competências nos treinamentos das suas equipes ou se apenas pertencem a um discurso descontextualizado da prática cotidiana, o que se 


\section{Modolo, F.; Menezes, R. P.}

caracteriza como uma das limitações deste tipo de estudo.

Destaca-se que o desenvolvimento da tomada decisão do goleiro na categoria sub-16 é crucial para a melhora do seu desempenho mediante diferentes confrontos apresentados ao longo dos jogos. O treino dessas capacidades deve estimular a percepção dos sinais relevantes da situação de jogo. Aspectos como o local da quadra, a posição do braço de arremesso e as trajetórias dos atacantes, devem ser desenvolvidos para que o goleiro possa antecipar o arremesso do atacante e aumentar as suas chances de conseguir defender (Modolo, 2017; Pascual Fuertes \& Peña Barceló, 2006). Além disso, deve-se planejar tarefas de treino que possam integrar o treinamento da tomada de decisão e o treinamento das técnicas específicas, o que pode tornar as reações dos goleiros mais eficazes (Helm, Reiser \& Munzert, 2016).

\section{APLICAÇÕES PRÁTICAS}

Apresentam-se como aplicações práticas dos resultados deste estudo uma possível definição/descrição de parâmetros técnicos e táticos relevantes para o treinamento do goleiro de handebol na categoria sub-16. Partindo-se do pressuposto de que esta seja a categoria relacionada à especialização do goleiro, o desenvolvimento da posição de base e dos gestos técnicos específicos são características fundamentais a serem enfatizadas, para que esse consiga jogar em alto nível de rendimento nas categorias subsequentes - sub-18/sub-21/adulta.

Para que isso ocorra, os parâmetros táticos determinantes para o rendimento do goleiro relacionam-se com a sua capacidade de perceber sinais relevantes da situação de jogo, como as características dos atacantes, as trajetórias préarremesso e o desenvolvimento do jogo colaborativo entre goleiro e defensores. Suscitase, portanto, que os treinamentos devam abordar não apenas os gestos técnicos, mas os processos inerentes à tomada de decisão que possibilitem responder a diferentes situações de maneira não estereotipada.

Os resultados também podem auxiliar os treinadores no planejamento das sessões de treinamento da categoria sub-16. No entanto, destaca-se que esses devem observar o desenvolvimento dos parâmetros supracitados a partir das características individuais dos goleiros, considerando vivências anteriores no handebol e em outras modalidades. Poderia estruturar sua atuação a partir das formas mais simples às mais complexas de estímulos, com vistas à eficácia nas decisões tomadas em jogo.

Por outro lado, cabe enfatizar a importância do goleiro para a fase ofensiva da sua equipe ao recuperar a bola e iniciar o contraataque, o que permite apontar a necessidade de desenvolver um bom passe e uma boa capacidade de percepção do posicionamento dos jogadores de quadra.

Este estudo apontou características aplicáveis a equipes de diferentes âmbitos escolar, clubes, vinculadas às prefeituras -, assim como abre um campo de discussão importante sobre a formação do goleiro de handebol, baseada na opinião dos treinadores, que se constituem como os agentes responsáveis por mediar o processo de ensino-aprendizagem.

Ouvir os treinadores sobre suas experiências práticas possibilita estabelecer contrapontos com as propostas de diferentes autores e construir saberes pautados também nas vivências, o que poderá tornar o estudo mais representativo para esses. Como perspectivas de estudos futuros salienta-se a necessidade de verificar como se apresenta o processo de ensino-aprendizagem nas categorias anteriores, identificando como os treinadores estabelecem o processo de formação do goleiro e nas categorias posteriores e os principais aspectos inerentes ao treino para que se jogue em níveis de rendimento cada vez mais elevados.

\section{REFERÊNCIAS}




\section{Características técnico-táticas: goleiros cadetes de handebol}

1. Alsharji, K. E. \& Wade, M. G. (2016). Perceptual training effects on anticipation of direct and deceptive 7-m throws in handball. Journal of Sports Sciences, 34(2), 155-162.

2. Anguera, M. T., Blanco-Villaseñor, A., Hernández-Mendo, A. \& Losada, J. L. (2011). Diseños observacionales: ajuste y aplicación en psicología del deporte. Cuadernos de Psicología del Deporte, 11(2), 63-76.

3. Anguera, M. T. \& Hernández-Mendo, A. H. (2013). La metodología observacional en el ámbito del deporte. E-balonmano.com: Revista de Ciencias del Deporte, 9(3), 135160.

4. Anguera, M.T., Portell, M., ChacónMoscoso, S. \& Sanduvete-Chaves, S. (2018). Indirect observation in everyday contexts: concepts and methodological guidelines within a mixed methods framework. Frontiers in Psychology, 19(3), 1-20. doi: 10.3389/fpsyg. 2018.00013

5. Antúnez Medina, A. (2003). La interceptación en la portera de balonmano: efectos de un programa de entrenamiento perceptivo-motriz. (Doutorado), Universidad de Murcia, Espanha.

6. Antúnez Medina, A., \& Garcia Parra, M. M. (2008). La Especificidad en la Condición Física del Portero de Balonamano. Ebalonmano.com: Revista de Ciencias del Deporte, 4(1), 5-12.

7. Antúnez Medina, A., García Parra, M. d. M., Argudo Iturriaga, F. M., Ruiz Lara, E. \& Arias Estero, J. L. (2009). Efecto de un programa de entrenamiento perceptivo-motor sobre la eficacia global de la portera de balonmano en competición. Cuadernos de Psicología del Deporte, 9(2), 31-43.

8. Antúnez Medina, A., García Parra, M. d. M., Argudo Iturriaga, F. M., Ruiz Lara, E. \& Arias Estero, J. L. (2010a). Programa de entrenamiento perceptivo-motor para mejorar la efectividad de la portera de balonmano. Revista de Psicología del Deporte, 19(1), 151-165.
9. Antúnez Medina, A., García Parra, M. M., Argudo Iturriaga, F. M., Ruiz Lara, E. \& Arias Estero, J. L. (2010b). Estudio piloto del efecto de un programa de entrenamiento perceptivo-motor sobre la eficacia en competición

la portera de balonmano según la situación del lanzador. RETOS. Nuevas Tendencias en Educación Física, Deporte y Recreación, 18, 29-34.

10. Arias Estero, J. L. (2009). El Portero de Balonmano. Revista Internacional de Deportes Colectivos, 4, 14-34.

11. Ato, M., López, J. J. \& Benavente, A. (2013). Un sistema de clasificación de los diseños de investigación en psicología. Anales de Psicología, 29(3), doi:10.6018/analesps.29.3.178511

12. Bayer, C. (1994). O ensino dos desportos colectivos. Lisboa: Dinalivros.

13. Bunker, B. \& Thorpe, R. (1986). The curriculum model. In R. Thorpe, D. Bunker \& L. Almond (Eds.), Rethinking games teaching (pp. 7-10). Loughborough: University of Technology.

14. Crusoé, N. M. d. C. (2004). A Teoria das Representações Sociais em Moscovici e sua importância para a pesquisa em educação. Aprender: Caderno de Filosofia e Psicologia da Educação, II(2), 105-114.

15. Côtè, J., Baker, J. \& Abernethy, B. (2007). Practice and play in the development of sport expertise. In R. Eklund \& G. Tenenbaum (Eds.), Handbook of sport psychology (pp. 184-202). Hoboken: Wiley.

16. Ehret, A., Späte, D., Schubert, R. \& Roth, K. (2002). Manual de handebol: treinamento de base para crianças e adolescentes. São Paulo: Phorte Editora.

17. Flick, U. (2009). Introdução à Pesquisa Qualitativa (Artmed Editora S.A. ed. Vol. 3).

18. Fraser-Thomas, J. L., Côté, J. \& Deakin, J. (2005). Youth sport programs: an avenue to foster positive youth development. Physical Education and Sport Pedagogy, 10(1), 19-40. 


\section{Modolo, F.; Menezes, R. P.}

19. Garganta, J. (1998). O ensino dos jogos desportivos (3 ed.). Porto: Centro de Estudos dos Jogos Desportivos/Universidade do Porto.

20. Graça, A. \& Mesquita, I. (2015). Modelos e conceções de ensino dos jogos desportivos. In F. Tavares (Ed.), Jogos desportivos colectivos: ensinar a jogar (pp. 9-54). (2.ed). Porto: Editora FADEUP.

21. Greco, P., Ferreira Filho, E. \& Oliveira Junior, T. F. (2002). Progama de Treinamento: iniciação do Contra-ataque. In P. Greco (Ed.), Caderno do Goleiro de Handebol (pp. 229-234). Belo Horizonte.

22. Greco, P. J. \& Benda, R. N. (2002). O Sistema de Formação e Treinamento Esportivo do Goleiro de Handebol. In P. J. Greco (Ed.), Caderno do Goleiro de Handebol (pp. 21-32). Belo Horizonte: Editora Philippka Verlag Minster.

23. Gómez-Millan, M. R. B. \& Esquiva, I. C. (2017). Diseño y validez de contenido de una entrevista para evaluación psicológica de porteros de fútbol. Revista de Psicología Aplicada al Deporte y al Ejercício Físico, 1(3), 1-12. doi: doi.org/10.5093/rpadef2017a3

24. Helm, F., Reiser, M. \& Munzert, J. (2016). Domain-Specific and Unspecific Reaction Times in Experienced Team Handball Goalkeepers and Novices. Frontiers in Psychology, 7, Article 882. doi: 10.3389/fpsyg.2016.00882

25. Lefèvre, F. \& Lefèvre, A. M. C. (2012). Pesquisa de representação social: um enfoque qualiquantitativo (2 ed.). Brasília: Liber Livro Editora.

26. Loffing, F. \& Hagemann, N. (2014). Skill differences in visual anticipation of type of throw in team-handball penalties. Psychology of Sport and Exercise, 15(3), 260-267. Doi: https://doi.org/10.1016/j.psychsport.2014.01 .006

27. Loffredo, M. \& Greco, P. J. (2002). Capacidade Técnica: Posições Básicas de Defesa da Bola. In P. J. Greco (Ed.), Caderno do Goleiro de Handebol (pp. 33-46). Belo Horizonte: Editora Philippka Verlag Minster.

28. Marconi, M. d. A. \& Lakatos, E. M. (2011). Metodologia científica (6 ed.). São Paulo: Atlas.

29. Matias, C. J. A. d. S. \& Greco, P. J. (2010). Cognição e ação nos jogos esportivos coletivos. Ciência \& Cognição, 15(1), 252271.

30. Menezes, R. P. (2010). O ensino dos sistemas defensivos do handebol: considerações metodológicas acerca da categoria cadete. Pensar a Prática, 13(1), 1-16. doi: 10.5216/rpp.v13i1.7269

31. Menezes, R. P. (2011). Modelo de análise técnico-tática do jogo de handebol: necessidades perspectivas e implicações de um modelo de interpretação das situações de jogo em tempo real. (Doutorado), Universidade Estadual de Campinas, Campinas.

32. Menezes, R. P. (2018). Ensino do handebol em longo prazo: estudo a partir da opinião de treinadores. Educación Física y Ciencia, 20(2), e048. doi:10.24215/1514-0105e 048

33. Menezes, R. P., Marques, R. F. R. \& Morato, M. P. (2016). Percepção de treinadores de andebol sobre as variáveis defensivas e ofensivas do jogo na categoria sub12. Motricidade, $\quad 12(3), \quad 6-19$. doi:10.6063/motricidade.4581

34. Menezes, R. P., Marques, R. F. R. \& Nunomura, M. (2015). O ensino do handebol na categoria infantil a partir dos discursos de treinadores experientes. Movimento, 21(2), 463-477. doi: 10.22456/1982-8918.47664

35. Menezes, R. P., Marques, R. F. R. \& Nunomura, M. (2017). Teaching handball to players under-12: the perspective of Brazilian coaches. Motriz, 23(4), e101792. doi: 10.1590/s1980-6574201700040006

36. Menezes, R. P., Reis, H. H. B. \& Tourinho Filho, H. (2015). Ensino-aprendizagemtreinamento dos Elementos Técnico-táticos defensivos individuais do handebol nas categorias infantil, cadete e juvenil. 


\section{Características técnico-táticas: goleiros cadetes de handebol}

Movimento, 21(1), 261-273. doi: $10.22456 / 1982-8918.46159$

37. Modolo, F. (2017). A Formação esportiva do goleiro de handebol: características apontadas pelos treinadores da categoria sub-16 (Mestrado), Universidade de São Paulo, Ribeirão Preto.

38. Oliver, D., Serovich, J. \& Mason, T. (2005). Constraints and opportunities with interview transcription: Towards reflection in qualitative research. Social Forces, 84(2), 1273-1289. doi:10.1353/sof.2006.0023

39. Pascual Fuertes, X. (2007). El entrenamiento del portero de balonmano: propuesta práctica sobre el desarrollo de la metodología basada en el tiempo. RFEBM Real Federación Española de Balonmano, 250, 8-16.

40. Pascual Fuertes, X. \& Peña Barceló, R. (2006). El portero de balonmano: una aplicación práctica de entrenamiento perceptivo-decisional ante lanzamientos de primera línea. Apunts: Educación Física e Esports, 84, 66-75.

41. Sá, P., Gomes, R., Saavedra, M. \& José Fernandez, J. (2015). Percepción de los porteros expertos en balonmano de los factores determinantes para el éxito deportivo. Revista de Psicología del Deporte, 24(1), 21-27.

42. Santos, W. R. \& Menezes, R. P. (2015). Os motivos para a especialização dos goleiros de handebol a partir dos discursos de treinadores experientes. Motriz, 21(2), 238-239.

43. Silveira, D. T. \& Córdova, F. P. (2009). A pesquisa científica. In T. E. Gerhardt \& D. T. Silveira (Eds.), Métodos de Pesquisa (pp. 3142). Porto Alegre: Editora da UFRGS.

44. Sousa, D., Prudente, J., Sequeira, P. \& HernándezMendo, A. (2014). Análise da qualidade dos dados de um instrumento para observação do 2 vs 2 no andebol. Revista Iberoamericana de Psicología del Ejercicio y el Deporte, 9(1), 173-190.
45. Thiengo, C. R., Vitório, R. \& Ferreira, L. A. (2006). O goleiro de handebol. Efdeportes.com - Revista Digital, 11(100).

46. Thomas, J. R., Nelson, J. K. \& Silverman, S. J. (2012). Métodos de pesquisa em atividade física. (6 ed.). Porto Alegre: Artmed.

47. Torregrosa, M., Chamorro, J. L. \& Ramis, Y. (2016). Transición de júnior a sénior y promoción de carreras duales en el deporte: una revisión interpretativa.

Revista de Psicología Aplicada al Deporte y al Ejercicio Físico, 1(6), 1-11. doi:https://doi.org/10.5093/rpadef2016a6

48. Triviños, A. (1987). Introdução à pesquisa em ciências sociais: a pesquisa qualitativa em educação (1 ed.). São Paulo: Atlas.

49. Wright, C., Carling, C., Lawlor, C. \& Collins, D. (2016). Elite football player engagement with performance analysis. International Journal of Performance Analysis in Sport, 16(3), 1007-1032. doi: 10.1080/24748668.2016.11868945

50. Zeir, U. (1981). El Portero de Balonmano. In J. D. Róman (Ed.), Estudio Monografico El Portero de Balonmano (pp. 3-46). Madrid: Instituto Nacional de Educación Física. 